\title{
Food Matters
}

\section{Arguments for an ethnography of daily care}

\author{
Hans Harbers*, Annemarie Mol**, Alice Stollmeyer***
}

published as:

Hans Harbers, Annemarie Mol \& Alice Stollmeijer, Food Matters. Arguments for an Ethnography of Daily Care, in Theory, Culture and Society vol 19 (5/6) 2002, 207-226

Special Issue on Sociality/Materiality. The Status of the Object in Social Science Edited by Dick Pels, Kevin Hetherington, and Frédéric Vandenberghe

* Department of Philosophy

University of Groningen

A-weg 30

9718 CW Groningen

The Netherlands

email: j.a.harbers@philos.rug.nl

** Department of Philosophy

University of Twente

Postbus 217

7500 AE Enschede

The Netherlands

email: a.mol@wmw.utwente.nl

*** Department of Philosophy

Centre de Sociologie de l'Innovation

University of Groningen

École Nationale Supérieure des Mines de Paris

A-weg 30

60, Boulevard Saint-Michel

9718 CW Groningen

75272 Paris Cedex 06

The Netherlands

France

email: a.stollmeyer@philos.rug.nl email: stollmeyer@,csi.ensmp.fr 


\section{Food Matters Arguments for an ethnography of daily care ${ }^{1}$}

Food is a wonderful entrance into practices, central as it is to both physical survival and social relations. It is therefore dissapointing that the sub-discipline Sociology of Food mostly behaves as if it were studying an aspect of social life, a sector of society. There are a few exceptions to this: sweeping studies that, departing from a food-detail, make a broad theoretical claim. Mintz' Sweetness and Power, for instance, rewrites the history of world wide capitalism from sugar 'up' (Mintz, 1985). And the essays collected in Golden Arches East intervene in discussions about globalisation through detailed ethnographic work on various - and highly varied - outlets of McDonald's in big cities in East Asia. (Watson, ed., 1997) The project this article does not achieve, but (im-)modestly proposes, while entirely different yet again, is similarly ambitious: to interfere in the deadlocked relation between biomedicine and ethics - with the taste of chocolate as a lever.

The socio-materiality of chocolate, or, more generally, of food, is crucial to the task at hand. Food is loaded with meaning, is grown and cooked by some people for others, who eat it jointly or alone, with all the social specificities this entails - while it is also physical. Living bodies die if they go without it. It isn't easy for the social sciences to face this, or, rather, to handle it. For up to and during the nineteen fifties, the social sciences made a space for themselves alongside biology and biomedicine by topicalising so-called social aspects of complex phenomena such as food, studied up to then as part of 'nature'. In order to achieve this, they carefully left the natural aspects alone. Terms were coined to separate out the aspects: gender next to sex difference; culture next to nature; kinship next to blood ties; illness next to disease. Gender, culture, kinship and illness became topics for the social sciences. Sex difference, nature, blood ties and disease were left in the hands of physicians and laboratory researchers.

Recently, however, such divisions are being blurred again. All former 'aspects' get mixed up in ethnographic descriptions of the practices in which they are being handled, so-called 'socio-material practices'. One might write various histories of this shift. It is possible to take it to be a next step in the development of post-structuralist theory and its fascination for material culture. ${ }^{2}$ Or one might say that it emerges out of the social studies of science and technology, where the work of physicians and laboratory researchers was desacrilised by studying it with methods originally designed for the study of preliterate tribes. Ethnographic description made the shiny technology used in laboratories ordinary and the objects of biomedicine accessible for study. ${ }^{3}$ And then there are the scholars concerned (politically, morally, personally) with the specificities of the way physicians and laboratory researchers actually delt with the sex difference, nature, blood ties and disease left in their hands. Among them as well hard work was done in order to reappropriate physicalities into social (but should we still call it social?) theory. ${ }^{4}$ Three histories, then, in which we might situate ourselves, and, as histories go, they are not external to each other. They intertwine. 
Food, meanwhile, even while its social and physical 'aspects' were not necessarily allways studied in unison, has all along remained a single word. ${ }^{5}$ No need, therefore, to bring its split-up aspects together again linguistically before writing about them jointly. We can start right away. And so we will. May we invite you to come along with us to a specific situation where the present deadlock in the relation between ethics and biomedicine manifests itself. By showing, not in general, but in this single case, how food matters, we hope to convince you of the importance of ethnographies of daily care.

Ethnographies that describe care as a socio-material practice and that, thereby, transgress the divide between ethical and biomedical versions of the good.

\section{The situation}

When he heard we were interested in questions to do with food in nursing homes, Paul told us about his mother. In the last stage of her life she had suffered from Alzheimer's disease. She was cared for in a nursing home and gradually ate less and less. Then for a while it was only possible to get her to eat or drink anything at all if it tasted like chocolate. And in the end she refused all food except for the small chocolates out of the box that Paul brought her. This was not enough to keep her going - so finally she died.

Dying from a lack of proper nutrition is a quite common way to go. It has been so for ages, not only in places and times of food shortage, but also in the middle of abundance. In present day nursing homes refusing food is a common way of retreating from life (Van der Heide et al, 1997). But who makes such retreats, when, how, why? And what kind of role is played, may be played, should be played by the people who work in nursing homes? Must they accept a person's refusal of food even if it leads to death or should they force feed for instance by pushing tubes through the nostrils and into the stomach?

In the Netherlands such questions suddenly became important public issues in the summer of 1997 (Stollmeyer, 1999). The newspapers (short of news to begin with) were filled with reports, debates, columns and interviews to do with questions of food and drink in nursing homes. The occasion for this discussion was the accusation by an elderly woman, Mrs. Mulder, that a nursing home in Groningen had attempted to murder her ex-husband, now 62 and with senile dementia. Mrs. Mulder was exhausted by taking care of her former husband, and had taken a break, so Mr. Mulder was in the nursing home as she went on holiday. For a while things went well, but then he gradually began to refuse all food and drink. The physician and the nurses talked about the situation and saw no reason to force feed him. However, when Mrs. Mulder returned she was furious and had Mr. Mulder transferred to the hospital where he was tube-fed. There were newspaper reports about his first day home again, where he was welcomed by his ex-wife and their daughter with a meal of spinach and mashed potatoes and a desert of custard.

In the Netherlands aggressive law suits against caring institutions such as nursing homes are rare. So Mrs. Mulder's intervention came as a shock. It 
also helped to bring out into the open the fact that food and drink and negotiations about them are of great importance in the daily care of elderly, demented and sometimes sick people in institutions. The question as to whether refraining from force feeding may indeed be murder or rather fits into the category of good care suddenly found itself on the agenda of Dutch public debate.

In the Dutch public debate around this issue two discourses dominated: an ethical and a medical one. They both have the same blind spot. This blind spot, or so we want to argue by means of a demonstration, becomes visible when one engages in an ethnography of daily care. Like the ethics of care tradition we take interpersonal relations spread out over time to be more important to the 'good' of care than dramatic moments where an individual will expresses itself or where fate is endured. But in addition to this we take it to be equally important to attend to the material dimensions of care. The catch word by which to summarise our text is: chocolate taste. This is not a theoretical term. But while theoretical terms have the advantage of traveling fast, good (short) stories tend to be more telling, catching and enduring.

\section{Public debate: free will and natural fate}

Mrs. Mulder's accusation of murder made journalists wonder whether what physicians had done here was indeed murder or not. Putting the question like this suggests that at least they had done something. That, more generally, physicians act when patients die after taking little or no food and fluids. Refraining from force feeding was presented as an active intervention. In this debate, the term mortify ('versterven' in Dutch) was taken out of its earlier Roman Catholic spiritual context and converted into a transitive verb. ${ }^{6}$ Doctors became capable of mortifying others, their patients. In this way a rhetorical link was made between the situation of people with senile dementia who stop eating and drinking and that much more widely and overtly debated issue - that of euthanasia - which in the Netherlands has been on the public agenda for more than a decade. Euthanasia entails the active involvement of a doctor and his or her pharmaceutical tools in the dying process of a patient who is severely ill. Patients who are in the process of dying but who suffer so much they feel they can no longer endure it, may ask a doctor to help them and to bring about death just a little earlier. In order for this practice to be acceptable all kinds of requirements have gradually taken shape. Crucial among these is that there is a clear, articulated and thus consciously uttered wish of the patient. The patient must have expressed his or her will to die and the professionals involved must be convinced that this will is not an artefact of pressure from family or others involved. The patient's will must be autonomous. Thus in the ethical discourse around euthanasia the most crucial terms are: will, autonomy, consciousness.

These exigencies make it all but impossible to practice euthanasia in a nursing home for those with dementia. After all, in the rationalist schemes where one is either compos mentis or not, the inhabitants of such homes are classified as demented, i.e. they are supposed to have no autonomously functioning or articulate will. As long as an ethics based on 'the autonomous conscious will' is accepted, no euthanasia is possible here: to intervene in order 
to end a demented person's life can only be classified as murder. Consequently, those who didn't want to take this view had to break open this ethical scheme. And indeed, some did. They argued that even if people are no longer articulate and have no properly functioning consciousness, they may still want something. Isn't refusing food and drink one of the means left open to people with dementia to express their wishes, a way in which they may speak, not in articulate terms, but with their whole being, through their body? And shouldn't then this wish be respected just as much as that of any other person? The argument enriched the ethical debate about euthanasia by suggesting that maybe the category of the will should be broadened from a will that expresses itself in a rational or at least articulate way, to what might be called a gutfeeling expressing itself in a gut-reaction. A will of a more physical kind.

There was yet another way out of the accusation of murder. Various physicians working in nursing homes stressed that the problem of demented patients who no longer eat or drink has nothing to do with that of euthanasia at all. Both problems, they said, are quite different. Contesting the idea that withering away involves wanting do to so, they tried to undo the association between the body acting (closing the mouth, turning the head) and anything like the conscious act of the will that is involved in euthanasia. 'The patients we are talking about do not refuse,' one of them wrote, 'they just don't like anything [to eat or to drink]'. Talking about refusal is already too close to attributing a will to the person who fasts. Instead, these physicians stressed that a lack of appetite and thirst is an element of being ill. It is not so much a gut feeling as a symptom of dementia. Dementia is a disease and the need for food and drink disappears as this disease progresses. This implies that mortification cannot be used in a transitive way. It is not something doctors may do to patients. It is hardly even something that demented patients do: it just happens to them. If there is an actor at all, it is the disease. Thus if a demented person dies as a result of fasting, this is not to be understood as a consequence of human intervention. It should be classified as a natural death.

So here we have two genres of discussing the issue of death through withering away. One is ethical. The crucial term is the will and the crucial question is whether or not to broaden up willing from a conscious and autonomous act to a physical expression of an embodied being. The other genre is cast in medical terms. Here, an association is made between need, disease and nature. Withering away is part of the natural course of dementia. Contrasting the two genres then raises the question about which to apply. What happens if a person with dementia in a nursing home stops eating and drinking: does this mean we are dealing with a person who refuses to live any longer (even if this is not a rational matter), someone who wants to die? Or does it mean that we are faced with someone whose vital energy is fading away? Is this a moment for ethical questions or the inevitable ending of a natural process?

However, posing the question as if there were only two alternatives (will or fate; ethical decisions or a natural course) leaves something out. For there is a third genre of relating to elderly demented people and their daily lives: one that is linked with care. In the newspapers we sometimes found remarks that alluded to this. A psychiatrist who works as a consultant for nursing homes remarked that relatives often have a hard time accepting that the staff doesn't 
shift to tube feeding when their parent stops eating and drinking. 'Often giving food and drink is the only thing one can mean to demented people. It feels like neglect to not mobilise all the technical means available to continue to do so.' Here there is no will - and no natural course either. Instead there are terms that allude to a caring relation in which it is important to mean something to someone and undesirable to neglect them.

Paul also talked about the way food, and especially chocolate, was tied in with his relation to his mother. 'Look, what I wanted is: I wanted to do her a favour. I wanted things to be as pleasant as possible for her... Of course I was not able, I thought, to visit her every day. Let alone of staying there for hours, which is what she would have preferred. So instead I came by every Sunday. I used to see her on Sundays. Somehow, however, I felt that that wasn't very often...So, so, what I did... I would buy chocolate, and tell [the nurses]: "Then you can give her the chocolate when I'm not there." And they said: "We will tell her 'It's from Paul,'” and then I would still kind of be there, you know?'

We were intrigued by the difference between this story and the other two genres, the ethical allusion to people's preferences as well as the naturalist evocation of the disease process in dementia. Medical ethics, tending to focus on moments of crisis, tries to tame these by reducing their complexity. A will or no will. A death wish or no death wish. The autonomous person speaking or the result of the pressure of others. The security such reductionist schemes tend to give may be comforting. It may give handholds and help to facilitate justifications after the events are over. But in the middle of the complexities of actual care the simplifying schemes of medical ethics make far less sense. For where do they leave Paul's good will and love; his time pressure; his lack of power to improve the situation; his fear - and the small material entity incorporating all of these: a box of chocolates?

At the other end of the spectrum, biomedical stories about the natural course of a disease are effective in public debates when it comes to countering the accusation of murder. These stories also inform caring practices physicians, after all, have an important say when it comes to overall policy questions in a nursing home. They have, e.g., the obligation and the right to sign or not sign the administration of tube feeding. But claiming that a disease has a 'natural course' is hardly helpful when it comes to the question how to give a shape to the day to day life of demented people actively (materially, culturally). How to do this? How is it done? In order to get to know more about this, it wasn't good enough to keep on reading. The reality of caring practices is underrepresented in public debates. ${ }^{8}$

\section{Materialities of daily care}

So it seemed a good idea to have a look at a ward. What are food (eating and feeding) and drink (drinking and giving someone to drink) in a nursing home? ${ }^{9}$ We asked this question as some sort of a we since at the time Alice was a graduate student in philosophy, supervised by both Hans and Annemarie. The three of us thought it was a good idea for Alice (who, after all, wanted to learn something and needed her degree) to look around in a psychogeriatric nursing 
home in Groningen. She sought permission for this and ended up in the very nursing home that had been accused of attempted murder by the upset Mrs. Mulder. The physician in charge received Alice, offered her tea, made a harsh joke about that ('We have a bad reputation when it comes to offering drinks, but can I offer you a drink?') and gave her permission for an ultra-short observation period of two days. Which we gratefully accepted. ${ }^{10}$

The nursing home in question is specialised in the care for psychogeriatic people, mostly with dementia. Dementia begins with loss of memory, but after a while other skills, like speaking, dressing and moving, also tend to gradually decrease. The care of the nursing home where Alice was to look around, or so one may read in the brochure that is handed out to new patients and their relatives, aims to slow down people's decline and preserve those skills they still have available. Some of the symptoms are treated. But the overall idea is to accept that this is a fatal disease. The brochure is quite explicit about the question what is done and left undone when a demented patient stops eating and drinking properly. We quote (obviously translating from the Dutch):

In case of food refusal the patient is encouraged, but not forced to eat, even if the refusal of food might lead to further weakening of the patient's condition. The nursing home is restrained about administering artificial food. Artificial food may be given in cases of a disorder from which recovery is possible. When artificial food is given, this is for a duration of time previously agreed upon. If recovery is not forthcoming and the condition does not improve enough for the resident to stay alive without artificial food, this is accepted as a sign of approaching death.

The very fact that this text exists and that patients and their families are so explicitly informed about the local policy, is historically linked up with the importance of the individual will such as it has been articulated in the ethical discourse. The point, here, is not some acute will to die. It is rather the will to live or not to live (or have one's relatives live) in a nursing home where the inability to stay alive without artificial food is 'accepted as a sign of approaching death'. Information, after all, is a necessary precondition for 'informed choice'. Hence the brochure. What is in the text, however, is clearly inspired by the other mode of reasoning that we came across in the newspaper articles. A medical mode of reasoning that stresses the importance of disease. Diseases speak through symptoms and signs and run a natural course. A part of the natural course of dementia is that, at a certain if unpredictable moment, the patient dies. The inability to eat and drink is a sign that this moment is approaching.

So the very first nursing home material that Alice brought along to the philosophy department contained the traces of the two dominant discourses that earlier we had come across in the newspaper articles: the ethical and the medical. The care we were after was, so far, only in the tea she had been offered (or the joke that supplemented it?). But on the days that Alice actually walked around on the ward care was present to an overwhelming extent. She was introduced to what in the nursing home is called a nursing ward, a ward 
where the residents need a lot of care and nursing (there are also wards for people in a less bad condition, a supporting and a caring ward respectively). All in all there are twelve units in the nursing home in question with up to fifteen residents living in each of them. So Alice spent two days in a nursing ward where she followed the work of the nurses and assistant-nurses, mainly the work of one of them whom we will call Julie, who was responsible for life in the living room.

A short visit like this doesn't yield a proper ethnographic note book with enough stories to give thick descriptions of just about any of the possible tensions or pleasures in which food and drink play a role. ${ }^{11}$ But it is enough to illustrate that in day-to-day care eating and drinking depend on more than just the will of individuals and the natural course of their disease. What matters in day-to-day care are people and the way they attend to one another. Care. But (and this, so far, is given far less attention in discourses surrounding care) what is of equal importance in the ward are materialities. Things. Tables, chairs, plates and, prominent among these, food itself. Food, eaten or left untouched, is more than an instrument of the will or a consituent of nature. It is more, but what? What does it bring about, food, what comes with it? In which ways does it matter? Let's have a look. Here is a day at the nursing home which in fact is a compilation of events Alice witnessed in the two days she went there.

The living room has an open kitchen with a low bar and two tables for breakfast. The living room has yet more tables: a big round one close to the kitchen, a small square one and, a little further away, a low coffee table surrounded by a few easy chairs. When I come in, two residents are already seated at the kitchen table. I help Julie to set it. Each seat has a plate, a fork and a glass. Then a bread-basket is also put on the table, a plate with cheese and a choice of meats, butter and all kinds of sweet spreads. One by one the residents enter, most of them hand in hand with, or supported by a nurse. Nicole, head of the unit, yells 'Good morning!' as if greeting everyone on behalf of the resident she brings in. After seeing me, she says to the residents at my table: 'You should eat well, because Alice is here today!' Everyone gets a glass of tea with sugar and a slice of bread which is cut into pieces. Some residents say what they want on their bread. Others are not asked anything. Julie says she knows their preferences.

I help a lady having breakfast. After I spread her bread with butter, I ask her what she would like on it. She talks about chocolate, and that she had it yesterday too. She looks around searching, discovers the chocolate confetti, looks carefully at the box and then gives it to me. I try to explain to her that this is the sugarfree chocolate confetti and that I will put the other one on her bread. 'This is for people who are not allowed to have sugar.' I don't know if she understands me, but she lets me have my way. After she has had a few bites, I ask her if it's nice. 'Yes... Chocolate doesn't become a bore easily.' I tell her I also like to eat chocolate. 'What?' 'Chocolate is nice to eat!' She smiles: 'Yes.' Her neighbour wants custard. Apparently that looks good, because after the bread with chocolate confetti the lady also wants custard. After finding a bowl, I start serving out the custard. Nicole tells me not to put too much in. The lady has recently begun to put on weight and grow out of her clothes, and her husband is not too keen on buying new ones. She only got a 
new dress for her birthday after a lot of persuasion from the nurses. 'Really sad,' says Nicole.

After breakfast - which takes a long time - Nicole distributes

medicines. After that, Julie, Nicole, the other nurses and I have coffee. At half

past ten it is time for coffee for the residents. Most of them are at the big, round

table in the living room. I take a stool and join them. Some residents need to be encouraged to drink something. I talk to them and pour new cups of coffee. Julie, Margreeth (another nurse) and I go to the canteen to have lunch at a quarter to twelve. They ask me about my first impressions and I tell that I find it hard to guess when residents should be left alone to eat and drink by themselves, and when they need help because otherwise they just won't do it. Margreeth and Julie explain that this becomes easier once you know the residents. On our way back to the unit we take the trolley with hot meals for the residents along: bowls with rice, ragout, green peas, apple-sauce and a pan of custard. The tables in the living room are set and the residents, wearing bibs, are at the table.

I am not able to help the nurses serving out the meals: I have no idea who wants what and how - carved, crushed and mashed, much or little... I walk along with Margreeth to a bedroom where a lady lies in bed. A radio is playing - rather loud - classical music. Margreeth feeds the lady with a spoon a so-called mix-meal, a 'kind of baby food' as she puts it, in which meat, vegetables and potatoes are mixed and mashed. I sit down a bit away from the bed, half hidden behind the radio. I feel awkward, as if here more than in the living room I am violating someone's privacy. The lady coughs and spits from time to time. I have the impression that she is about to cough up the food, but Margreeth gives her the next spoonful. The lady doesn't eat much. She wriggles her feet, turns away her head and stares at the ceiling. Margreeth tells me afterwards that she pushed the spoon away with her tongue. Margreeth tries a few more spoonfuls: 'Just look.' Then the lady keeps her mouth tightly closed. Margreeth puts the bowl aside and remarks to me: 'See how little she eats?' But the lady eats all her custard. Margreeth carefully cleans the lady's mouth.

At half past two it is time for tea. On the table is a plate with cookies. Some people for whom I pour tea have a chat with me. Sometimes they suddenly live in the past. A gentleman tells me that this morning he didn't want to get up. Then all of a sudden he continues talking about an airplane we had to catch: 'You were there too.' An almost blind and stone-deaf lady has her cup of tea in front of her. I hand her the cup and speak loudly in her ear: 'Here's your tea, you may as well drink it while it's still warm!' But she protests, and then I see that a small fragment is missing from the rim of her cup. I turn the other side of the cup toward her and try again. However, she responds by saying that the tea is for me. And no matter how clearly I tell her that I already had tea and that this one is for her, I don't seem to get through to her.

By four o'clock the nurses and I have tea, together with the nurses who are just beginning their shift. Our shift is over. I say goodbye to the residents. On the corridor I meet a friendly, gentle man who thinks life in the unit is too busy. He always eats fast, often at a quiet table, and then leaves immediately going into the corridor. There he strolls around or he sits dreaming in one of the arm-chairs next to the elevators. That's where I meet him this afternoon. 
When I walk toward him his face lights up. I tell him I am about to go home, shake his hand and get a big kiss from him. 'Bye,' he says, 'bye.'

There is not all that much to do on the ward. Eating and drinking structure the day and its rhythm. That makes them important, not just as nutrition but as events as well. What time is it? It is time for breakfast or it is time for tea. ${ }^{12}$ Chairs are pushed across. The kitchen tables are used in the morning, the big round table for lunch. But while eating and drinking are important as events and structure time, not everybody is all that keen to get in food or drink. So a system of encouragement is in operation. ${ }^{13}$ To some extent this is explicit and verbal encouragement (which the nurses give selectively, being so familiar with the residents, they say, that they exactly know who to encourage and who to leave alone). But a lot of implicit encouragement is incorporated into other ways of working. The nurses sit at the table with the residents and react to what they want and do immediately. If people are responsive, the nurses ask them what they would like to have on their bread, choosing special spreads for them. They mash or mix dinner when this helps it being eaten. They go into people's rooms when they are bed-ridden and feed them, mixing an entire bowl beforehand, even if only five spoonfuls are likely to be eaten.

All in all nurses spend a lot of time and effort attending to the specificity and the various relevances of food and eating, drink and drinking. In day-to-day care an important aspect of eating and drinking is in their sociability (having people eat together makes them eat better: seeing someone else eating custard may lead a resident to ask for some as well; but sociability is not simply a way of encouraging eating: it is also an end in itself for which eating and drinking provide the means: come and join us for coffee - even if you would prefer the quietness of the corridor). Another important aspect of food and drink is their texture (in separate chunks, mashed or mixed; warm but not too hot). And then, of course, there are taste preferences. The Dutch breakfast with bread and cold things to put on it: slices of cheese or meat and an impressive variety of sweet things. Chocolate that doesn't become a bore.

Paul says that once his mother was in the nursing home she missed the way eating used to be something she had discretion over. All her adult life she had cooked the family food and, after the death of her husband, her own. She had done it to her own taste. ${ }^{14}$ But with the onset of the dementia she started to make mistakes. Used to gas, she had had trouble when she had to shift to electricity: she often forgot to turn off the cooking plate. So her food burned and Paul was afraid the house would catch fire. The food in the nursing room just came as and when. His mother had nothing to say about it. ${ }^{15}$ It happened to be quite different from what she cooked for herself. This, he said, was part of her dislike for it. He excused the institution. 'Of course they cannot serve potatoes to one person, pasta to the next and pie to a third.' However, Paul had been pleasantly surprised, he said, by the creativity of the nurses once his mother started to refuse to eat the normal food on offer. When they found out that chocolate-taste did the trick, they bought chocolate milk for her instead of the usual milk. They also went out of their way to buy a diet product meant for sick people: there happens to be one tasting of chocolate. Feeding this to Paul's mother, the nurses cleverly combined a medical attitude towards food 
(appreciating it for its nutritional value) with a caring attitude (which tries to accommodate and please a person).

Back in our philosophical department, talking about Alice's field notes, we realised we had hit on the blind spot of the ethical concern with people's will (to live or die) as well the medical concern with diseases and their course (natural or the subject of intervention): the taste of chocolate. In the ethical discourse the specificities of food or drink themselves are never attended to food and drink are treated as mere means to an end, survival, that may be desirable, or not. In the medical discourse food and drink do get attention, but only one of their characteristics is of importance: how well do the various nutrients involved serve the the goal of physical survival, and to which extend may they prevent dehydration? The food and drink of daily life, however, the food and drink that are relevant to caring practices, have so many more qualities. They taste good or too salty or not sweet enough or simply nasty. They are too cold or too hot. Potatoes and meat may be mashed or mixed. The tea may have or not have the right amount of milk in it. The list of things that matter is virtually endless. Words of encouragement. The setting of the table. The wheels under one's chair. The sound of others eating. Bibs that protect clothes. A whole gamut of practicalities, of simultaneously social and material ingredients, thatshape daily dealings with food and drink in nursing homes.

These are more than varied means to a single end, but together generate sadness or give joy. ${ }^{16}$

In both ethical and medical discourse food and drink are taken up in an instrumental way, only the perspective shifts. The ethicists are mostly concerned with the goals: whose goals, when, and why should the instruments 'food and drink' serve; whose will or whishes must preside? The medical discourse delves into the quality of the means: when are which kinds of food and drink the most suitable building blocks for an organism and when are they no longer serving life? In a context of care, however, food and drink are not means for physical survival. They are media for care - they do care. They taste good or bad, have a nice or gruesome texture. They are, not as delegates of people, but all by themselves, objects of longing or aversion. It is thus that attending to food and drink in all their daily life complexity is a crucial part of caring.

'The nurses told me', says Paul, 'that sometimes she would spend half an hour on a single piece of chocolate, my mother. These are small pieces! She would lie there and very quietly suck on it. And then a smile would glide over her face. I tried to tell myself that this small moment of bliss was due to the fact it was my chocolate melting away in her mouth. But it may well have been just the taste. She liked the taste of chocolate.'

\section{Ethnography and normativity}

Most debates around issues that have to do with fasting, tube feeding and death through starvation in nursing homes are currently framed in either an ethical or a medical way. The opinions expressed within these discourses clash - and yet there are also alliances between them. ${ }^{17}$ Together, so to speak, they divide the 
world. Questions may arise as to which phenomenon fits where. Is the fasting of demented people a matter of the will or a course taken by nature? Where should it be located? Such questions, however, arise against the shared background assumption that in this world they co-exist, will and nature. Each has its own realm and each should be dealt with in a repertoire specifically adapted to it. But what if, as we have argued here, they also share a blind spot: the taste of chocolate - the materialities so crucial to care practices? Then the question as to what happens if we attend to these forgotten (f)actors arises.

Care has been drawn into theory in the ethics of care which has radically amended the way 'the will' is framed in ethics. The ethics of care started explicitly as a critique of Kantian and utilitarian as well as liberal conceptions of the autonomous subject who makes rational choices. ${ }^{18}$ Instead of isolating individuals with their personal acts of will, the ethics of care has foregrounded relations between people. Instead of focusing on rational arguments about universal moral principles it has shifted to practical deliberations about the various available courses of action in specific situations. Instead of taking everybody to be equal in principle, it has tried to grasp what the power differences that actually exist between us mean for the possibility of 'doing good'. But so far a humanist orientation has dominated the ethics of care. The relevant entities in its theoretical repertoire are human beings. ${ }^{19}$ This implies that while the theoretical notion of the will has been subjected to considerable change, its counterpart, nature, has been left unanalysed in this tradition.

In the specific case of dementia this means that the idea that this might be a disease with a 'natural course' is left unexamined. And it shouldn't be. For while it makes sense to invoke the fate brought on by nature when one relates to ethicists who seek a will that shapes our lives in a masterful manner, stressing the inevitably of death as the outcome of dementia, skips over the fact that we die in different ways. Some people die fast, others take a long time. Some have moments of bliss, others do not. Some are well cared for, others die alone. Or, to say a lot in a condensed way: some get food and drink tasting of chocolate, while others do not. A concept such as nature is unhelpful when it comes to articulating this. In contrast, a theoretical repertoire that attends to the materialities and practicalities of care pushes one to ask the question how (culturally, materially) to give shape to the course of our diseases. ${ }^{20}$

This, then, may lead on to the question of how to give a good shape to the course of our diseases - or at least a shape that is less bad than its alternatives. The question of what good care might be is currently also taken up in two major ways. One is ethical, one professional. It is in line with our argument so far that we think that separating out these two styles of normativity is problematic. For in daily practice there are many ways to orient oneself towards norms such as 'autonomy' or 'health' or 'the good life' or 'quality' but if it makes sense to separate them out at all then this is hardly in terms of a distinction between ethics on the one hand and professionalism on the other. ${ }^{21}$ As it is, the more striking difference between ethical and professional modes of attending to the good has nothing to do with the norms towards which they are oriented, but rather with the styles of assessing what does or does not count as meeting those norms. In a professional context, the dominant style is that of research, of setting standards and then measuring the extent to which the care 
given is 'effective' or 'efficient' in meeting these. ${ }^{22}$ In ethics, whether deontological, utilitarian or liberal in character, the dominant style of relating to the good is to judge single decisions by weighing the arguments for and against them. The justification for a decision may be based primarily on principles, or take moral intuitions and even background notions into account. ${ }^{23}$ But it always aims to come to a firm conclusion.

Engaging in an ethnography of the practicalities and materialities of daily care makes one conceive of the goodness of care in a way that differs from both the professional and the ethical approaches. ${ }^{24}$ Instead of an investigation that sets out to find to what extent given standards are met, the question to be explored is which standards are set up in the day to day practice of caring. What goods are strived after in practice, which bads are painstakingly avoided? Answering such questions, requires attention to the specific issues - like the taste of chocolate - that are at stake in care practices. Ethnography also comes with its own time frame. Instead of passing judgement in a single, difficult moment - say the moment Mr. Mulder is or isn't tube fed - a far longer period of time comes into view. The entire trajectory of a patient may have been handled well or may look like a succession of mistakes, neglect and negligence. Ethnography calls for attention to the dynamics of collective, socio-material, practices. Instead of attending to the care offered to single individuals, the issue is rather to attend to the modes of care given on a particular ward, or in an entire nursing home.

Ethnography as a mode of attending to the goodness of care is obviously very different from passing well argued judgements. But this does not imply it is necessarily a matter of mere description. ${ }^{25}$ What is required instead is involved description: ethnographic work that looks for contrasts, sets up differences and seeks for what one practice might learn from another. If we want to study how, in day to day practices, 'good' and 'bad' are being done, engaging in such a study may well be recognised as itself a practice - doing good, bad, or rather both. This implies that an involved ethnography of daily care is not out to ground some theory of justice, but is a quite different way of engaging in moral philosophy. It is a way that involves story telling about the activities of people (their caring work, their intentions, their concerns) and about the activities of things (tables, bibs, tastes, temperatures, textures). These stories do not present bare facts. They have, or work towards having, a moral. They articulate the moments at which one feels one is intruding, the occasions when there are tensions, where there is hurt - and also point out those locations where the good is sought or enacted in one or other of its variants. Instead of passing a verdict about a given question, these stories open up new questions. They sensitise their readers to the specificities that characterise different modes of caring. And with different modes of care come different modes of dying and of living. 


\title{
Notes
}

\begin{abstract}
${ }^{1}$ We would like to thank Jeannette Pols, for the example she set with her ethnographic research in nursing homes and for stressing the importance of day to day practicalities; the friend who goes here by the name of Paul, for sharing his story and insights with us; the residents and staff of the (here nameless) nursing home were Alice was allowed to come and observe; the editors of this special issue and our various anonymous reviewers; and John Law for his intellectual support and for correcting our English.
\end{abstract}

${ }^{2}$ See e.g. Tilley, ed. (1990). Or, more interesting, the later, more dynamic and practice oriented development of post-post-structuralism in the great journal Raison Pratiques (E.g. Akrich a.o., 1993). In ethnographic work in the non-West material culture has been present as a topic of at least some investigators all along - see for a recent series of examples Arnoldi, Geary and Hardin, eds. (1996).

${ }^{3}$ Our favorite here is Latour (1988). The social studies of science later also moved away from the lab-bench: good examples of what things do in and with organisations may be found in Law (1994). In the social studies of science there was a shift away from the head of the scientist-thinker towards the hands of the scientist-tinkerer. But this may/should also entail a shift of attention towards other professionals: laboratory technicians, secretaries.

${ }^{4}$ For the sex/gender distinction, see: Haraway (1991), for kinship/blood ties : Strathern (1992), for disease/illness : Lock et al, eds. (2000) and Mol (2002).

${ }^{5}$ Social geography and social medicine have in common that throughout the second half of the twentieth century their place among the social sciences was problematic since they never went along with the social/nature divide. They didn't fit into grand theory discussions, while they took it to be their task to understand specific varieties of socio/naturality - such as the situatedness of a city along a river or differences between the incidence of high blood pressure between the US and Japan. Food, too, was studied in both these disciplines. We do not go into that intriguing history here since methodologically we almost exclusively build on ethnography. But see e.g. the contributions to: Nast and Pile, eds. (1998).

${ }^{6}$ For the use of this term, see: Chabot (1996). The term 'versterven' wasn't common in present day Dutch any more. For the practice that used to come with it, abstaining from food and drink for a while so as to be able to attend better to spiritual matters, had all but died out itself - with many other Roman Catholic traditions. It seemed however a good word to revitalise in this somewhat different context, even if here the crucial issues are not primarily spiritual in character. Seeking how to write about our topic in English, we found 'mortify' in the dictionary as the traditional equivalent of 'versterven'. However, since English language countries have not yet taken up this word in the new context of elderly people in nursing homes, it is likely to sound strange to you. Which again shows the impossibility of noise-free translation. \{Inserted later: Correction! It may not sound strange to you at all, the term 'mortification'. One of our reviewers was so kind as to point out to us that Goffman (1961) uses it, and indeed: 'Upon entrance, (...) he[the recruit] begins a series of abasements, degradations, humilations, and profanations of self. His self is systematically, if often unintentionally, mortified.' (p. 14). Goffman is concerned with the effacing of the self of inmates in institutions. The 'mortification' the present text is concerned with is of a more physical kind. It leads to overall death, of self and body.\}

${ }^{7}$ A Dutch physician working in a nursing home has written a book about his daily experiences in which, likewise, big terms like will and nature give way to stories about daily, often painful events. See Keizer (1994).

${ }^{8}$ This is obviously, among other things, a gender-issue. Our favorite reference here still is a (by now old) historical analysis of nursing professions showing how they were set up as the housewife's counterpart to the male doctor's husband role. (Spijker, 1981) Since then, a lot of work 
on this topic has been done. We do not go into it here. We do not even overtly attend to the gender aspects of food itself, however rich the topic. (See e.g. Counihan, 1999). This is not just because one cannot do everything in every text. We also take the generalising of what might also been genderised as an occasionally useful feminist strategy.

${ }^{9}$ For a further discussion of semiotic 'what are' questions, i.e. inquiries into what entities are through comparison with what comes near to and thus constrasts with them, see Mol and Mesman (1996). There this semiotic method is also compared in detail with a symbolic interactionist way of working, that explores the perspectives of nurses rather than tracing activities and enactments of food.

${ }^{10}$ Alice indeed used this field work also for her master's thesis, that we plundered and added on to for the present article. For a publication that more closely follows the thesis, see Stollmeyer (1999).

${ }^{11}$ The tradition of ethnographically describing medical and nursing practices is an impressive one that we are aware of but do not aim to do justice to in the present context. For one of the many collections of examples, see Lindenbaum and Lock (1993). And then there is the tradition of ethnographically or sociologically describing food practices - that again is rich and remains mostly absent here. For a good overview of that broad field of study, see Mennell, Murcott and Van Otterloo (1992).

${ }^{12}$ Sellerberg (1991) interestingly topicalises the relation between time, food and drink in nursing homes. She, however, does not topicalise things, but follows the perspectives of people, stressing the difference between staff, for whom time-schedules are working-schedules, and residents, whose mealtimes are at stake.

${ }^{13}$ The theoretical ancestor to name when it comes to attending to the ways in which institutions encourage and discourage the people living in them, is obviously Goffman. (See in relation to nursing homes especially Goffman, 1961) Goffman had the theoretical and political audacity to suspend the trust (so widely shared by the elite of his days) that institutions serve their inmates, and act in their best interest. What he came up with instead was an indictment. He accused institutions of going against the interests of their inmates, and more specifically of crushing, not just their autonomy but their very selves. For a recent, more ethnographic, example in the same indignant style, see Diamond (1992). We do not want to repeat these accusations, nor fall back into trust again, but take the occasion of doing field work as one in which it is possible to study the very standards that Goffman and his audience seemed to share. So we do not know, but wonder, what, in practice, 'a person's interest' is taken to be by those involved; what 'autonomy' is made to be and what the lack thereof; and what the 'selves' are that are either undermined or strengthened.

${ }^{14}$ Crouch and O'Neill (2000) stress that acquiring a highly personal taste for food is historically novel. What one ate, used to be linked up primarily with availability and social habit. It is only recently that 'some of the needs of self-concious individuation (...) are met through eating practices based on personal choice rather than social habit' (p. 181). If this is right, if food is becoming important to 'identity formation' in ways in which it hasn't before, institutions will have to find creative ways to adapt to a next generation of people whose identity is at stake when they eat. For a collection of essays where the link between food and identity is further explored, see Caplan, ed. (1997)

${ }^{15}$ Working as a nurse assistant, Alice has recently done more field work in another nursing home. Here, while she worked there, a system of choice was introduced. All residents were invited to fill in a form every week with a few choices to make for every day's meal. However, since, due to their dementia, none of the residents were able to fill in such a form alone, it took the nurses an enormous amount of time (time they didn't have) to do so with them. The choices offered, moreover, often didn't speak to many of the residents. This was partly due to the actual food offered (many among the older generation of Dutch people never considered the choice between rice and pasta, but ate potatoes with every hot meal). However, the issue of 'choosing food' in the first place seemed not to speak to many residents. While the people 
responsible for the kitchen are indeed trying to adapt to the recent 'personalisation' of food, most residents just want to eat what they are used to. All in all, as Alice noted down in her notebook, the nurses ended up filling the forms.

${ }^{16}$ That joy is not self-evidently given and something one may passively enjoy, but the outcome of a 'subject-network' in which social and material ingredients are permanently attaching and mutually adjusting, is beautifully argued (with the example of Bach amateurs and drug addicts) in Gomart and Hennion (1999).

${ }^{17}$ One might take the tension between the ethical and the medical approach we signal here as an occasion for a sociology of professional groups in tension. However, we carefully try to abstain from that endeavour, since our aim is not to unmask others from the outside, but to mix and mingle, to convince, and to make a difference to the inside. But see e.g. the contributions to Weisz (1990).

${ }^{18}$ Classics are Gilligan (1982) and Noddings (1984). Tronto (1987) detaches ethics of care from a gender-issue and generalises it to one of the care sector as a whole. For elaborated discussions on ethics of care, see, for example, Manschot and Verkerk (1994).

${ }^{19}$ There are obviously exceptions. We've come across one in Dutch, written by colleages who, just like us, tried to incorporate materialities into ethical discussions: Berg and Van de Lyke (1997).

${ }^{20}$ Like nursing practices medical practices themselves also give shape to 'disease' in highly diverging ways. For a collection of articles which analyse the 'multiplicity' of what they no longer call 'nature', see Berg and Mol (1998).

${ }^{21}$ It is interesting in this respect to follow the concept of 'quality of life' as it moves between ethical, economic and medical discussions. See e.g. Nussbaum and Sen (1993). But it is not just with the notion 'quality of life' that medicine looses its orientation on a unified and naturalised health. Since it was errected as a norm health has never been unproblematic to/in medicine. See for the history of this norm Canguilhem (1989); and for a comment on its multiplicity, Mol (1998).

${ }^{22}$ For an example of a deconstruction of establishing the ideal of 'effectivity' in a sciencecentered and 'technical' way, see Lettinga and Mol (1999).

${ }^{23}$ The notion of a 'reflective equilibrium' acknowledges the three-way traffic between moral intuitions, moral priniciples and relevant background theories without one of them being a foundation for the other two. In that sense it accepts the non-foundationalist, and in principal circular character of moral reasoning. See Rawls (1971), and Daniels (1979). Nevertheless, almost all attention within normative theory goes to the principles, as if moral intuitions and background notions are relatively unproblematic. We break with this asymmetry and foreground moral intuitions and background notions - while leaving open the question whether doing so still leaves room for principles, or not. That is, we engage in what we call 'empirical philosophy' - here applied to normative issues. See also the special issue on empirical philosophy of the Dutch journal Krisis. Tijdschrift voor empirische filosofie, 1(2000)1.

${ }^{24}$ Foucault suggested that we should go beyond Kant by no longer refusing to transgress certain limits in order to achieve universality, but by, instead, seeking for the idiosyncratic in what presents itself as universal. The method he proposed for doing so was archeological. Here, we follow his plea to engage in a philosophy that attends to what is 'singular, contingent, and the product of arbitrary constraints', but suggest ethnography as a complementary mode of going about this task. See Foucault (1984).

${ }^{25}$ See De Vries (1989) for an early intervention from a STS-perspective into ethical debates. De Vries argues that the new task of ethics is 'to inform us on the implicit rules and concepts that underlie existing practices, in order to make them publicly accessible.' (p.290) We also argue for ethnographic descriptions, but try to avoid opposing 'description' and 'being 
normative'. Instead, we try to learn from those who analyse the normativity engrained in modes of writing, see e.g. Prins (1997), Woolgar, ed. (1988), Clifford and Marcus, eds. (1986). 


\section{References}

Akrich, Madeleine a.o. (1993) Les objects dans l'action. De la maison au laboratoire. Special Issue of: Raison Pratiques.

Arnoldi, Mary Jo, Christaud Geary and Kris Hardin (eds.) (1996) African Material Culture. Bloomington: Indiana University Press.

Berg, Marc and Saskia van de Lyke (1997) 'De normativiteit van een infuus-pomp. Over zorgpraktijken en technologie' in Marian Verkerk (ed.) Denken over zorg. Utrecht: Elsevier/De Tijdstroom: 173-188.

Berg, Marc and Annemarie Mol (eds.) (1998) Differences in Medicine. Unravelling Practices, Techniques and Bodies. Durham: Duke University Press.

Canguilhem, Georges (1989 [orig. 1966]) The Normal and The Pathological. New York: Zone Books.

Caplan, Pat (ed.) (1997) Food, Health and Identity. London: Routledge.

Chabot, B. (1996) 'Versterving, een oude weg naar Rome' in B. Chabot, Sterven op drift; Over doodsverlangen en onmacht. Nijmegen: SUN: 177-189.

Clifford, James and George E. Marcus (eds.) (1986) Writing Culture. The Poetics and Politics of Ethnography. Berkeley: University of California Press.

Counihan, Carole (1999) The Anthropology of Food and Body. Gender, Meaning and Power. New York and London: Routledge.

Crouch, Mira and Grant O’Neill (2000) 'Sustaining identities? Prolegomena for inquiry into comtemporary foodways’ Social Science Information 39 (1): 181-192.

Daniels, Norman (1979) 'Wide Reflective Equilibrium and Theory Acceptance in Ethics' The Journal of Philosophy 76: 256-282.

Diamond, Timothey (1992) Making Gray Gold. Narratives of Nursing Home Care. Chicago: University of Chicago Press.

Foucault, Michel (1984) 'What is Enlightment' in: Rabinow, Paul (1984) The Foucault Reader. New York: Pantheon Books.

Goffman, Erving (1961) Asylums. Essays on the Social Situation of Mental Patients and Other Inmates. New York: Anchor Books.

Gilligan, Carolyn (1982) In a Different Voice. Psychological Theory and Women's Development. Cambridge Mass.: Harvard UP.

Gomart, Emilie and Antoine Hennion (1999) 'A sociology of attachment: music amateurs, drug users' in John Law and John Hassard (eds.) Actor Network Theory and After. Oxford: Blackwell Publishers: 221-247.

Haraway, Donna (1991) Simians, Cyborgs, and Women. The Reinvention of Nature. London: Free Association Books.

Heide, A. van der, M.T. Muller, J.G.C. Kester, J.H. Groenewoud, G. van der Wal and P.J. van der Maas (1997) 'Frequentie van het afzien van (kunstmatige) toediening van voeding en vocht aan het levenseinde’ Nederlands Tijdschrift voor Geneeskunde 141 (40): 1918-1924.

Keizer, Bert (1994) Het refrein is Hein. Dagen uit een verpleeghuis. Nijmegen: SUN. 
Latour, Bruno (1988) The Pasteurization of France. Cambridge, Mass.: Harvard University Press.

Law, John (1994) Organizing Modernity. Oxford: Blackwell Publishers.

Lindenbaum, Shirley and Margaret Lock (eds.) (1993) Knowledge, Power \& Practice. The Anthropology of Medicine and Everyday Life. Berkely: University of California Press.

Lettinga, Ant and Annemarie Mol (1999) 'Clinical Specificity and the Non-generalities of Science. On Innovation Strategies for Neurological Physical Therapy’ Theoretical Medicine and Bioethics 19: 517-535.

Lock, Margaret, Allan Young and Alberto Cambrosio (eds.) (2000) Living and Working With the New Medical Technologies. Cambridge: Cambridge University Press.

Manschot, Henk and Marian Verkerk (eds.) (1994) Ethiek van de zorg. Een discussie.

Amsterdam: Boom.

Mennell, Stephen, Anne Murcott and Anneke H. van Otterloo (1992) The Sociology of Food: Eating, Diet and Culture. London: Sage. Trend report in Current Sociology 40 (2).

Mintz, Sidney (1985) Sweetness and Power. The Place of Sugar in Modern History. New York: Vicking Penguin.

Mol, Annemarie (2002) The Body Multiple. Ontology in Medical Practice. Durham: Duke University Press.

Mol, Annemarie (1998) 'Lived reality and the multiplicity of norms: a critical tribute to George Canguilhem’ Economy and Society 27 (2\&3): 274-284.

Mol, Annemarie and Jessica Mesman (1996) 'Neonatal Food and the Politics of Theory: Some Questions of Method' Social Studies of Science 26 (2): 419-444.

Nast, Heidi and Steve Pile (eds.) (1998) Places through the body. London and New York : Routledge.

Noddings, N. (1984) Caring . A Feminine Approach to Ethics and Moral Education. Berkeley: University of California Press.

Nussbaum, Martha and Amartya Sen (eds.) (1993) The Quality of Life. Oxford: Clarendon Press.

Prins, Baukje (1997) The Standpoint in Question. Situated Knowledges and The Dutch Minorities Discourse. Utrecht: University of Utrecht, dissertation.

Rawls, John (1971) A Theory of Justice. London: Oxford University Press.

Sellerberg, Ann-Mari (1991) 'Expressivity within a time schedule: subordinated interaction on geriatric wards' Sociology of Health and Illness 13 (1): 68-82.

Spijker, Truus (1981) Mooi en beschaafd verplegen. Lochem: De Tijdstroom.

Stollmeyer, Alice (1999) 'Voedsel in het verpleeghuis: lichaam, geest of meer?' in Hans Harbers and Sjaak Koenis (eds.) De bindkracht der dingen, Special Issue of Kennis \& Methode 23 (1): 102-128.

Strathern, Marilyn (1992) After Nature. English kinship in the late twentieth century. Cambridge: Cambridge University Press.

Tilley, Christopher (1990) Reading Material Culture. Oxford : Basil Blackwell. 
Tronto, Joan (1987) 'Beyond Gender Difference to a Theory of Care' Signs 12 (4): 644-663.

Vries, Gerard de (1989) 'Ethische theorieën en de ontwikkeling van medische technologie' Kennis \& Methode 13 (3): 278-294.

Watson, James (ed.) (1997) Golden Arches East. McDonald's in East Asia. Stanford: Stanford University Press.

Weisz, George (1990) Social Science Perspectives on Medical Ethics. Dordrecht: Kluwer Academic Publishers.

Woolgar, Steve (ed.) (1988) Knowledge and Reflexivity. New Frontiers in The Sociology of Knowledge. London: Sage Publications. 


\title{
Food Matters \\ Arguments for an ethnography of daily care
}

\begin{abstract}
In public debates about the desirability of force feeding in the Netherlands the inclination of people with dementia to refrain from eating and drinking tends to be either taken as their gut-way of expressing their will, or as a symptom of their disease running its natural course. An ethnographic inquiry into daily care, however, gives a quite different insight in fasting by relating it to common practices of eating and drinking in nursing homes. In a nursing home eating and drinking are important social activities that may be shaped quite differently. And while necessary for survival, food and drink also have other qualities: taste, temperature, texture, smell. Whether we want it or not, in the end we all die. But with different modes of care come different modes of dying - and of living.
\end{abstract}

